\title{
LA REPARACIÓN DEL DAÑO EN LA JUSTICIA PENAL
}

\section{DAMAGE REPARATION IN CRIMINAL JUSTICE}

\author{
Lucía Barboni Pekmezian
}

Universidad de Granada, España

\author{
Javier Valls Prieto \\ Universidad de Granada, España
}

\begin{abstract}
Resumen: El objetivo de esta comunicación, es introducir al lector en el modelo de Justicia Restaurativa como una respuesta alternativa y/o complementaria al modelo clásico de Justicia Retributiva, entendiendo el acto delictivo como un hecho que trasciende la transgresión de las normas establecidas por la ley. Para esto, acudimos a los estudios pioneros en la temática. Las prácticas que ofrece el modelo restaurativo, apuestan a un cambio cultural en dos ámbitos: en la forma de responder al conflicto que supone la delincuencia en una sociedad y en el forjamiento de nuevas sensibilidades en sus integrantes.
\end{abstract}

Palabras Clave: Justicia restaurativa, justicia juvenil, reparación

\begin{abstract}
The aim of this work is to introduce the Restorative Justice model as an alternative and / or supplemental response to the classic model of Retributive Justice, understanding the criminal act as a fact that transcends the contravention of those standards set by the law. For this, we turn to the literature on pioneer scholars in the field. The restorative practices model suppose a cultural change in two areas: how to respond to conflict that involves crime in a society and the forging of new social sensibilities.
\end{abstract}

Keywords: Restorative justice, juvenile justice, reparation

\section{Trascender al castigo}

Tal y como expresa Wright (1996, p.23), los procesos judiciales se basan fundamentalmente en definir "quién es culpable y quien no, quien gana el juicio y quien lo pierde". Nos preguntamos: ¿Son realmente las anteriores, preguntas que queremos responder en la justicia desde el marco de la reinserción social?, ¿es correcto pensar en la justicia únicamente desde la culpabilidad y el castigo?, ¿ha servido hasta ahora dicho modelo?

Entendemos que el condenar a cierta pena, sanción o castigo a un sujeto, contempla casi exclusivamente la retribución a la sociedad de aislar de la misma a quien ha infringido un daño a algo o alguien según la ley, o bien de cumplir alguna alternativa a la privación de libertad, como forma de intimidarle ${ }^{1}$. En países como

1. Véase Juanche, A., \& Palummo, J. (2012). Hacia una politica de Estado en privación de libertad. Diálogo, recomendaciones y propuestas. SERPAJ. Uruguay.
Uruguay hasta hace relativamente poco tiem$\mathrm{po}^{2}$, ni la intervención de técnicos profesionales, ni la rehabilitación formaban parte del encuadre carcelario práctico en la Justicia Penal de adultos.

Cuando hablamos de castigo y de los modelos de justicia que los avalan, surgen un sinfín de teorías, conceptos y debates en los que no pretendemos introducirnos, dado que nuestra intención es aproximarnos a un modelo puntual y no detenernos en cada unos de los existentes. Este es el enfoque disciplinario que hace el modelo de justicia restaurativa (de aquí en más JR) en el que se trabajan y potencian las relaciones humanas, diferenciándose de la finalidad de una sanción, más propia de un modelo de justicia retributivo. El modelo de retribucionismo clásico parte de la idea de que

2. Véase Ley presupuestal No. 18.719 aprobada en Diciembre de 2010 a través de la cual se suprime la Dirección Nacional de Cárceles y se unifica el sistema penitenciario desde la creación del Instituto Nacional de Rehabilitación. 
la pena es precedente de un acto delictivo y un castigo compensa el perjuicio producto de dicho acto y es por tanto, una respuesta directa y proporcionada a un delito (Torres Rosell, 2006). Allí radica una de las grandes diferencias entre estos modelos: mientras el modelo retribucionista se enfoca en la manera de evitar o bien reducir el delito a través de la amenaza e intimidación, generando temor a la sociedad desde el Derecho Penal; el modelo restaurativo pretende contribuir a la concienciación social, promoviendo valores antagónicos a la violencia, favorecedores del encuentro personal y el encuentro social y fundamentalmente de un equilibro a la actual asimetría de las sociedades, a través de la reparación, la responsabilización y el diálogo (Segovia Bernabe, 2010).

En definitiva, un comportamiento desajustado que perjudica a otro, es ante todo, una ofensa a las relaciones interpersonales (Stutzman Amstutz \& Mullet, 2005) y es por tanto que el modelo en cuestión hace hincapié en responsabilizar al ciudadano de sus obligaciones y desde allí, crear soluciones que reparen el daño ocasionado y el vínculo humano. Entendemos que se trata de un paradigma idóneo en el sentido de su posicionamiento desde la inclusión comunitaria en los conflictos sociales, pues el "sentirse o no, parte de", tiene mucho que ver con la concientización de un sujeto en relación a sus derechos y obligaciones. Resulta casi imposible cuantificar el mal actuar de un sujeto y más aún, de poder cuantificarse el castigo, éste tiene efectos diversos en cada sujeto, con lo cual " (...) nadie puede decir que una semana en prisión es más o menos severo que $x$ meses o años en libertad condicional, y/o cantidades de multas" (Wright, 2003, p.16).

Cuando hablamos de medidas privativas de libertad, tanto en el contexto de jóvenes, como de adultos, no podemos dejar de mencionar las ideas de Garland (2007) en relación a la prisión como institución social. Existen diferentes ideas y posturas en relación al simbolismo y significado del castigo y una de las cuestiones en las que estamos ampliamente de acuerdo con el sociólogo es que el castigo aplicado en sí mismo y de forma aislada, conduce ciertamente al fracaso a la hora de controlar a la sociedad. En acuerdo con lo que el autor expresa, la prisión ha venido a sustituir otras formas de castigo que hoy día culturalmente son inaceptables, sin embargo las consecuencias de este tipo de institución parecen ser las mismas a las aplicadas siglos atrás, escondidas bajo una diferente etiqueta.

Quienes defienden los modelos retributivos, tienden a subestimar las finalidades y efectos de la JR, en contraposición a resoluciones inmediatas y tajantes, como el internamiento o la prisión. Sin embargo, lejos de tratarse de procedimientos blandos, la JR no solo es directa y personal, sino que pone en juego aspectos emocionales que realmente pueden hacer la diferencia, entre la concientización o no concientización del daño cometido por parte de quien ha delinquido, algo que otro tipo de respuesta penal no logra alcanzar (Walgrave, 2001). A su vez, a nivel psicológico, el tipo de efecto que suele conseguir la situación de enfrentamiento con la víctima para el infractor, tal y como se da en la mediación (la principal práctica restaurativa) suele ser muy fuerte e impactar al individuo en su futura vida dadas las emociones que se generan en dicha situación, como ser el miedo, la vergüenza, la humillación, culpa, etc. La víctima logra un papel más poderoso, en el que puede o no aceptar las disculpas, mientras que quien ha delinquido tendrá la posibilidad de ponerse en un lugar más vulnerable en el que podrá ser "des-acusado" de culpa. Cuestiones que no se ven abordadas en las medidas privativas de libertad, quedando entonces fuera un sinfín de procesos fundamentales inherentes a la resocialización.

La urgencia del cambio de paradigma, parte entre otras cosas, del marco actual de Justicia Penal en Latinoamérica, repleto de vulneraciones de $\mathrm{DDHH}$, carencia de infraestructura y recursos humanos y superpoblación carcelaria. Puntualmente en el ámbito juvenil, nos encontramos con países como Costa Rica, con una legislación que promulga un máximo de 15 años de privación de libertad a los menores; con el testimonio (Fumeiro, López, Gómez, \& De Achá, 2011) de un $35,28 \%$ de jóvenes que expresa haber sido maltratados por funcionarios (Fumeiro et al, 2011); con países como Bolivia, Colombia, Ecuador y Paraguay que no incluyen las alternativas de mediación y/o conciliación en sus legislaciones (Fumeiro et al, 2011); y con un $50,44 \%$ de privaciones de libertad devenidas de un delito contra la propiedad. Aún cuando se establece en las diferentes legislaciones que dicha privación de libertad puede ser impuesta excepcionalmente y en delitos graves (Fumeiro et al, 2011). Cuestiones como las anteriores, 
son tan solo algunos de los tantos ejemplos que evidencian las dificultades que la región tiene en la materia de Justicia Juvenil.

Sin ir más lejos, en Montevideo el internamiento en centros de régimen cerrado, viene siendo la medida "socio-educativa" más adoptada en los últimos años, mientras que las tasas de delincuencia no reflejan reducción en la violencia utilizada para cometer infracciones, sino que por el contrario, la rapiña va en ascenso (López \& Palummo, 2013). Desde allí es entonces que deberemos situarnos para analizar la funcionalidad y eficacia de este tipo de medida.

Una de las importantes conclusiones de las investigaciones y argumentaciones establecidas por los distintos autores citados, es que en general, hay un consenso entre los estudiosos del campo, en que el internamiento en centros cerrados es una medida ineficaz y contraproducente, sin embargo, sigue siendo una respuesta reiterada a la delincuencia cometida por jóvenes. Uno de los principales problemas radica en la finalidad de las intervenciones y a la vez, en los medios utilizados para ejecutar las mismas, pues difícilmente se alcance la resocialización o prevención de delincuencia desde el aislamiento. Dicho aislamiento, entendido como un castigo, es generalmente patológico y de consecuencias nada favorables, siendo por el contrario otro tipo de tratamientos, como los programas psicológicos y las medidas restaurativas mucho más eficaces (Redondo Illescas, 2010; Fattah,1998; Geudens, 1998).

En definitiva, todo apunta a un fracaso de las sanciones duras, que se concentran en los síntomas del acto criminal en lugar de enfocarse en sus causas, (Pellon \& Palladino, 2011) una cuestión que implica el trabajo combinado entre el Estado e Instituciones capaces de implementar proyectos y programas. Esto último es fundamental en el sentido que no podemos atribuir toda la responsabilidad al Derecho Penal. Existe una coordinación entre el trabajo multidisciplinar que también está fallando. En este punto es que el trabajo de los equipos técnicos que trabajan para la justicia, comprendidos por psicólogos, asistentes sociales, criminólogos y educadores sociales, es imprescindible, al igual que su especialización técnica en el área (Barton, 2000). La intervención, el seguimiento, el aporte de redes a los usuarios, la implementación de estrategias de prevención y reducción de reincidencia son algunas de las tantas cuestiones que el castigo per se no contempla. Es entonces que ya sea desde la alternativa y/o complemento, entendemos que es imprescindible el considerar los objetivos a los cuales el modelo de JR apunta.

\section{¿Por qué la Justicia Restaurativa?}

La JR viene cobrando cada vez más fuerza en las últimas décadas, fundamentalmente tras lo que algunos autores consideran que ha sido la crisis de los modelos rehabilitadores y la vuelta a los retributivos (Gordillo Santana, 2007), la introducción a la Victimología dentro del campo de la Criminología y la cualidad flexible e informal propia de su modelo, que brinda un rol activo y decisivo a los individuos involucrados en un delito y su entorno.

A la vez, las normativas internacionales, recomendaciones y directivas cada vez más hacen énfasis en la preferencia que debe darse a las prácticas que tengan en cuenta la pacificación social y la reparación del daño y la víctima cuando de criminalidad se trata así como un entendimiento de ésta por parte del Derecho Penal, que trascienda las penas, las medidas de seguridad y el castigo. La reparación es entonces una de las premisas básicas desde las cuales se plantea el modelo de JR, abarcando el daño a repararse, los aspectos materiales y económicos, pero también y sobre todo, el sufrimiento ocasionado a la víctima y a su entorno más próximo, la inseguridad social que el mismo ocasionó y la indignación de la comunidad en relación al hecho, en definitiva, todas aquellas cuestiones circundantes al delito (Walgrave, 2008). Esta idea es fundamental para comprender la importancia de la reparación del daño de forma simbólica, en tanto el delito, trasciende a ser un mero hecho.

Si buscamos una manera constructiva de encarar los conflictos en las sociedades, estaremos estableciendo una diferencia entre la prevención y la destrucción, una de las formas de afrontarle con constructividad, son las prácticas inherentes a la JR, que a pesar de plantearse como un novedoso paradigma, han sido llevadas a cabo desde siempre en las diferentes comunidades, de diversas formas. Este tipo de prácticas son conocidas como la mediación entre víctima y agresor, el grupo de diálogo restaurativo (conferencing), los círculos de paz, etc.

La herramienta que representa el conferencing puede ir dirigida a diferentes situaciones y 
no únicamente en el ámbito delictivo, en el que se encuentran víctima y agresor, sino que también puede ser llevado a cabo entre familias. En el primer caso, que es el que nos compete, se incluye no solo a la víctima y al victimario sino a la policía y a víctimas secundarias que hayan podido verse perjudicadas en el acto delictivo $o$ que estén interesadas por apoyar a alguna de las partes para poder llegar a un acuerdo final bien, a través de un guión que proponga el facilitador de la conferencia o siguiendo alguna guía de apoyo que permita que el encuentro sea fructífero. En definitiva se suma a la propuesta la comunidad como agente activo, lo cual resulta sumamente favorecedor tanto para la víctima como para el agresor y para la sociedad en general.

Los círculos de paz son un programa similar al de conferencing, en el sentido que incluyen a víctimas secundarias pero agregan la posibilidad de que se adhiera algún miembro de la comunidad interesado en participar en el caso. Todos los participantes se sientan en círculo y generalmente quien ha cometido el delito comienza explicando el suceso y así, uno a uno, mientras el cuidador del círculo (keeper of the circle) se encarga de que el proceso esté protegido.

Se trata de un modelo que deja a un lado la sanción como castigo en su sentido estricto y pretende alcanzar la reparación a través de la inclusión de la víctima, el agresor y la comunidad en dicho proceso y el diálogo entre dichas partes como proceso comunicacional imprescindible para llegar a un acuerdo y resolución eficaz. Este modelo, se basa en la importancia del vínculo humano y el relacionamiento interpersonal y el peso que éste tiene, tanto en el origen, como en la solución del conflicto social. El castigo obstruye las posibilidades de restauración dado que el foco absoluto en éste, hace que se deje a un lado la atención adecuada a la víctima y al daño consecuente (Walgrave, 2008). Existen otras formas de censurar las conductas delictivas, pero la de infringir dolor no es la vía que utiliza la JR.

En líneas generales entendemos que la $\mathrm{JR}$, atendiendo a las diferencias culturales y contextuales, puede tratarse de una alternativa interesante a plantearse con preferencia a otras medidas, por varios motivos:

- mayor agilidad en el sistema de justicia: consideramos que de hacerse un mayor uso de recursos como la mediación, deberían haber menos demoras en los juzgados por la menor cantidad de inicios de procedimientos.

- mayor coherencia con la normativa nacional e internacional;si bien a nivel legislativo (también en acuerdos, recomendaciones, etc) se promulgan ciertos derechos, deberes y convenios, no siempre se cumplen en la práctica y uno de los ejemplos más claros es el de la adopción del internamiento como última ratio. Con la posibilidad de contar con otras medidas alternativas que no conlleven la apertura de archivo ni el inicio de un procedimiento penal nos acercaríamos más a lo que las normativas exponen y a los efectos que estas pretenden.

- participación de la víctima en el procedimiento; tal y como mencionan Aertsen, Bolivar, Mesmaecker y Lawers (2011) las víctimas, cada día más, quieren deshacerse de la etiqueta que se les asigna tras su victimización y hacer algo al respecto, en lugar de permanecer ajenos al proceso aportando únicamente como testigo de los hechos. A través del modelo de JR la víctima adquiere un nuevo rol, en el que la vulnerabilidad se convierte en un concepto definido por los estudiosos del modelo como uno de los objetivos y valores fundamentales del mismo, en el cual los individuos tienen el poder de optar entre las alternativas a su alcance para resolver y superar un conflicto. Refieren esto como empowerment, lo cual en español sería dar un paso a la acción, motivarse, haciéndose partícipes a través de la puesta a punto de sus necesidades y cómo y cuando estas podrán ser logradas.

- responsabilización por parte del infractor; Los aspectos preventivos y la cuota justa de protección creemos que deberían estar implícitos en un modelo de justicia, pero sin dejar de lado el factor responsabilidad, a través del cual hay un reconocimiento del sujeto de su acto y posiblemente asociado a éste un aprendizaje y mayor posibilidad de rehabilitación.

\section{La importancia de la reparación}

Para introducirnos en el mundo de la JR, no podemos dejar de lado que "la justicia restaurativa es un producto no finalizado" (Walgrave, 2008, p.11) y si bien se trata de un modelo que viene instaurándose desde hace más de dos décadas, su implementación se va extendiendo mundialmente cada vez más como un "movimiento social" (Walgrave, 2008, p.11). La mayor parte de autores coinciden en que se trata de una práctica de compleja definición, y por 
ejemplo, mientras según algunas legislaciones puede tratarse de una medida alternativa, en otras no puede considerarse una medida, sino una posibilidad, una oferta que surge desde el Ministerio Fiscal, pero que por su principio de voluntariedad y por tanto la imposibilidad de imponerse per se, no puede considerarse una medida. Se trata de un modelo que apunta a intervenir en el funcionamiento de las comunidades y su reparación a través de prácticas más informales, en las que tanto víctimas como agresores pueden expresarse más adecuadamente que en un juicio oral.

El objetivo principal de la JR es la reparación de los daños causados por el hecho delictivo, a través de un encuentro de diálogo entre las partes, y no la rehabilitación del agresor o la prevención de la reincidencia, sino que estos dos últimos serán posibles efectos que surjan desde dicho objetivo, pero no se apunta directamente a que se cumplan (Put, Vanfraechem, \& Walgrave, 2012). Es por lo anterior que se abren varias interrogantes cuando de medir la efectividad se trata, ya que ésta depende fundamentalmente de lo que se entienda por eficacia, esto puede ser en términos de reducción de reincidencia o del sentimiento de satisfacción de los participantes posterior a su ejecución.

Nosotros entendemos que una práctica restaurativa no deja de tener un resultado positivo en caso que a mediano o largo plazo exista reincidencia, pues si se cumplió el objetivo de reparación de la misma en su momento, la reiteración del delito no la convierte en un fracaso. Es fundamental agregar, que entendemos la reparación como una acción que trasciende a lo material, para convertirse en algo simbólico y de mayor significado.

En la JR, a diferencia de los modelos penales tradicionales, la víctima no es el estado y el crimen no es la infracción de una ley y con ésta la búsqueda de culpables y el castigo pertinente a estos (Zehr, 2005). Es debido a que la víctima es el estado, que dado su carácter impersonal y abstracto, en la justicia retribucionista no hay lugar para la reconciliación ni el perdón. Es por tanto que aparece la necesidad de un cambio de óptica a la hora de analizar y evaluar la delincuencia, sus efectos y posibles soluciones. En este sentido aparece de lleno la importancia del restablecimiento de los vínculos en una comunidad. Si pensamos en un joven que comete una infracción con un vecino, un maestro o inclusive algún familiar, ¿cómo podrá reintegrarse éste a su contexto post-ejecución de la medida, sin una previa reconciliación o reparación? Es complejo pensar en una adecuada reinserción al ambiente habitual con tensión y sentimientos de venganza de por medio, en definitiva, repercusiones que llegan a ser destructivas a nivel colectivo, reduciéndose la interacción social, fomentando la estigmatización (Medina, 2003).

Existen diversos valores en juego a la hora de llevar a cabo la JR que son fundamentales para entender el marco de su funcionamiento. Es a través de ellos que se da el sentido a la intervención restaurativa y la evaluación de la misma. En líneas generales son los siguientes (Stutzman Amstutz, 2009):

- Todos los individuos deberían ser tratados con dignidad y respeto, teniendo en cuenta que cada persona posee un trozo de la verdad.

- Todos necesitamos ser responsables de nuestras acciones y por tanto reparar las mismas cuando hace falta.

- Todos somos miembros de una comunidad y por tanto tenemos una conexión con quienes nos rodean.

- Todos debemos reconocer que el perdón es un proceso que nos permite avanzar.

- Generamos oportunidades de reconciliación cuando nos sentimos afectados por las acciones de otros.

- Si queremos acercarnos al funcionamiento del modelo, debemos hacer mención a la base de las 3R: restoration, responsability y reintegration.

Con el primer objetivo, se pretende lograr la reparación de la víctima, tanto a nivel moral como material por parte del infractor quien será enfrentado al delito cometido a modo de hacerle responsable de su acción y por ende lograr el segundo objetivo. Con los dos anteriores objetivos alcanzados, se promueve la finalidad educativa que logre favorecer su reinserción a la comunidad (González Tascón, 2010). La restauración o reparación puede entenderse en cualquier ámbito y en cualquier momento y con esto queremos decir que no se puede limitar a cierto tipo delictivo, como erróneamente se cree y tampoco parece haber un plazo de tiempo que limite su implementación, sino que siempre existe algo que reparar y nunca es tarde para ello. Con esto último hacemos referencia a aquellos casos en los que, debido a que el agresor, por ejemplo, se encuentra en prisión, o el proceso haya sido de larga duración, no quiere decir que desde el centro penitenciario en 
el que se encuentra, o inclusive posteriormente a la ejecución de la sanción, no pueda llevarse a cabo un proceso de mediación o conferencing. El crimen, aunque de forma negativa, genera un lazo, una relación entre un sujeto y una comunidad y es por tanto fundamental, reconstruirlo de forma constructiva, para que se vuelva lo más positivo posible (Stutzman Amstutz, 2009). Se otorga una especial importancia a la concepción del crimen como una violación de las relaciones, en las que dicha violación genera un deber: el deber de reparar el mal ocasionado.

Se define la JR como un proceso que invita al consenso y la participación de todas las partes, entendiéndose por partes las víctimas, los victimarios y quienes se hayan sentido perjudicados por el delito en cuestión, tales como familiares, vecinos y que tiene diversos objetivos (Marshall, 2003). Dentro de dichos objetivos, se plantea poder cubrir a nivel informativo a la víctima a modo que ésta comprenda para qué sirve este tipo de proceso y así pueda expresar sus sentimientos y lograr la reparación; y por otro lado, apunta a que quien ha cometido el delito se libere de culpas, tenga la oportunidad de reparar y disculparse a través de la concientización de que no solo se ha infringido la ley, sino que también deberá hacer frente al daño que ha hecho a otras personas. El crimen divide y separa a las personas de sus comunidades y la JR trabaja para que estas partes se reconcilien, entendiendo que los roles de víctima y victimario son temporales. En definitiva, más que una práctica, se trata de un conjunto de principios que implican el involucramiento de las personas afectadas por una acción, la visión de la criminalidad como un conflicto propio de un contexto social, la flexibilidad y una mirada enfocada a la búsqueda de soluciones de un problema (Marshall, 2003).

En este sentido, nos parece destacable mencionar la exitosa experiencia de la mediación entre privados de libertad de ETA (Euskadi Ta Askatasuna) en el centro penitenciario de Vitoria y sus víctimas (Pascual, 2013). En dicho proceso de mediación, si bien se trató de una práctica con sus debidas complejidades, fue posible llevarla a cabo en tanto que las partes decidieron por su propia cuenta querer involucrarse acorde a sus propias necesidades y sin generalizar las respuestas a darse, pues estas no representan a todas las víctimas ni a todos los agresores por igual. Lo fundamental es llevar a cabo respuestas que promuevan la paz a tra- vés de la humanidad y las garantías del proceso. En este caso la eficacia de la práctica de mediación es evaluada a través de la satisfacción de las dos partes involucradas en el proceso. A la vez cabe destacar como en este ejemplo, la mediación es llevada a cabo en la propia ejecución de la pena y bajo la condición impuesta por las víctimas de que no existieran reducciones de la misma por involucrarse los agresores en la práctica, con lo cual hablamos de un proceso con finalidad reparadora en su totalidad, en la que el único y máximo objetivo es la reparación de la víctima, de la cual se desprende, también la reparación en cierta medida del agresor, quien tenía la necesidad de pedir perdón y de interesarse por el bienestar de quien fue su víctima años atrás. Aun así, existe una cuestión muy cierta y también controvertida a nivel conceptual entre los estudiosos de la JR en la fase ejecutoria y es que las prácticas restaurativas llevadas a cabo dentro de dicha fase, suponen una contradicción con los principios del modelo.

Existen efectos psicológicos devastadores en una persona que ha sido víctima de un delito, fundamentalmente si hubo violencia en el medio y es por esto que se considera de gran importancia el tipo de respuesta que se da a la delincuencia y sus efectos y lo efectivas que pueden ser las técnicas propias de la JR en este aspecto. En cuanto a esto, se plantea el crimen desde una violación del Yo (Zehr, 2005), de lo que uno es como humano, sus creencias y su espacio personal y como efecto se crea un trauma, indiferentemente se trate de un delito más o menos grave, sino acorde a cómo el sujeto lo vive dado que se alteran dos supuestos existenciales básicos: la creencia en nuestra autonomía y en un mundo con orden y significado. Dichos sentimientos generan un sinfín de preguntas, que necesitan ser respondidas para que la persona vuelva a armarse y a encontrar sentido a su vida; al poder que ejerce en esta y del que fue despojado durante una agresión.

Dentro de las necesidades de las víctimas, se destacan las siguientes (Wright, 1998):

- Ayuda con los efectos prácticos y emocionales del crimen y su rol de víctima.

- Información y noción del proceso.

- Ser tenido en cuenta con seriedad y respeto.

- Recibir disculpas y/o algún tipo de compensación.

- Seguridad en relación de la no repetición de los eventos. 
En este sentido es que fundamentalmente la JR se ocupa de la víctima, algo que en otros modelos de justicia no queda tan claro o simplemente no es tenido en cuenta. Nosotros lo entendemos como un círculo que se retroalimenta, en el cual los efectos de su ejecución van constructivamente influenciando en las partes involucradas. Es decir, de una medida restaurativa, se desprende una ex víctima con necesidades y con interés en ser reparada, pero también con la posibilidad de generar un aprendizaje en el agresor; por otro lado se desprende la inclusión del agresor como algo más que un mero culpable, como un humano que tiene la posibilidad de expresarse, reparar de diversas formas su mal actuar, pedir perdón y ser perdonado, cambiando su rol en la comunidad y teniendo la posibilidad de reintegrarse adecuadamente a esta. Pensamos que desde este punto de vista es imposible considerar la JR como un modelo naïve, sino que es imprescindible entenderla como una posibilidad más humana y natural, en la que se rompe una relación y ésta puede ser enmendada y no necesariamente a través del castigo.

La JR promueve el efecto favorecedor de las relaciones que tienen las diferentes herramientas de este tipo de respuesta, fundamentalmente para que el infractor comprenda no solo el daño causado, sino la ruptura de las normas sociales y el reconocimiento de la misma, para así entender los derechos de la víctima y como les ha vulnerado (Walgrave, 2007). Así, se logra una mayor concientización del daño que la que puede obtenerse únicamente con la adopción de una sanción y a su vez se dirige a la forma en la que este daño podrá ser reparado y no solo al castigo que podría imponerse al agresor. Entonces se entiende el crimen desde el perjuicio provocado y no únicamente desde la mera transgresión al orden y en el encuentro entre víctima e infractor, se llegará al acuerdo en el que se establezca la vía por la cual enmendar el daño. Consideramos esta última idea como fundamental para acercarnos, no solo al concepto en sí de resocialización, sino a la idea de los roles que los sujetos que han delinquido ocupan en una sociedad, que no parece comprender que por infringir la ley en ciertas circunstancias no se puede etiquetar a la persona como delincuente de por vida, ni aun sujeto que ha sido víctima, a serlo también de por vida. En cuanto a esto, no podemos dejar a un lado los posibles efectos que a largo plazo pueden tener en el agresor el hecho de estar privado de libertad y sin posibilidad de llevar a cabo alguna práctica restaurativa y que, probablemente, nunca podrá confrontar los estereotipos que han influenciado negativamente en su agresión, ni aprender habilidades sociales positivas para su reinserción o reconocer su responsabilidad en los hechos y las distintas formas a través de las cuales podría reparar sus efectos (Zehr, 2005). Esto último pensamos es de estricta consideración, pues de lo contrario no estamos generando ningún efecto ni influencia positiva sobre los sujetos, convirtiéndose la medida sancionadora en un castigo sin sentido.

Consideramos útil esta apuesta que lleva a cabo la JR de dar un nuevo rol, una nueva posición a quien ha delinquido. Desde la psicología este cambio de rol tiene efectos en varios sentidos de la vida del joven, fundamentalmente porque se le está dando la posibilidad de asumir su error y hacer algo al respecto y por sobre todas las cosas, se crea la posibilidad de aprendizaje. Pues si bien no todos los seres humanos tenemos el mismo grado de empatía, ni los mismos valores, pensamos que se trata de una oportunidad que en muchos casos, de ser bien ejecutada, puede ofrecer exitosos resultados en un doble sentido, ya que es una experiencia de aprendizaje tanto para el agresor como para la víctima y en cuanto a esta última, como representante de la sociedad el resultado que el proceso a ésta le ofrezca es decisivo. Lo es en cuanto que la vivencia de esta experiencia, siendo positiva tendrá mucho peso y repercusión en el resto de la comunidad y por tanto, un posterior efecto en las creencias sobre la misma en cuanto a la delincuencia. Pensamos que si en los modelos más retribucionistas puede considerarse que el daño es reparado con castigo, entonces una vez finalizada la condena, el agresor ha saldado su cuenta con la sociedad, pero sin embargo nada se ha hecho para que se produzca una responsabilización de su parte en los hechos, ni un aprendizaje que prevenga futuras agresiones, ni se ha atendido a la víctima, por lo que fácilmente podrá volver a delinquir, nuevamente "endeudarse" con la sociedad, y volver a "pagar la deuda" y así.

Para cerrar este apartado, concluimos en líneas generales lo que la JR busca conseguir entre las partes (Subijana Zunzunegui, 2012):

- La comprensión del hecho en sí mismo.

- La responsabilización por parte de quien ha cometido el daño. 
- La creencia en la potencialidad de un desarrollo personal.

- La recreación del vínculo dañado.

- El compromiso de la comunidad.

\section{Reflexiones Finales}

Evidentemente, como toda teoría, ésta tiene sus críticas, sus fortalezas y debilidades, inclusive algunos autores llegan a plantear que no se trata de una alternativa a los castigos, sino un castigo alternativo (Walgrave, 2001). A su vez se debe tener en cuenta que en algunos países no se aplica a ciertos tipos delictivos ni tampoco en casos donde tanto por la conducta, como por la personalidad del sujeto que ha cometido el delito, sea considerado ineficaz y contra producente, al fin y al cabo su efectividad será proporcional a los objetivos que se pretendan lograr con el agresor - aunque actualmente y cada vez más, se está logrando extender a todos los ámbitos, inclusive en delitos graves-. Una de las críticas que ha recibido este tipo de modelo, es en relación a la posición en la que quedan las víctimas, al servicio del delincuente, estando implicado el riesgo de una segunda victimización y los peligros que esta conlleva.

Para lograr sus cometidos estarán en juego múltiples factores y condiciones y claro está, que su puesta en práctica no es tan sencilla como puede parecer mientras se describe, es por esto que el personal que represente el rol de mediador o facilitador, deberá estar formado ampliamente en las técnicas.

La JR se estaría realizando tres preguntas básicas: ¿Quién ha sido herido?, ¿Qué tipo de necesidades tiene?, ¿De quién son las obligaciones involucradas con esto? Mientras que la justicia tradicional punitiva se pregunta:¿Quién es el culpable?, ¿Qué hecho ha cometido?, ¿Qué leyes ha infringido? (Zehr, 2002). Es fundamental, a la hora de cuestionar la coherencia de un modelo y su adaptación a un determinado contexto, la legitimidad de las medidas que ofrece para sancionar a un individuo, a la vez que deberíamos preguntarnos si realmente tenemos evidencia científica de la utilidad y efectividad de las mismas antes de su imposición (Trépanier, 2000).

A la vez consideramos de gran importancia dentro del ámbito de justicia, destacar que hay cuestiones que trascienden al Derecho per se y es por tanto que el trabajo multi-disciplinar y la comunicación entre las partes y todas las instituciones correspondientes al campo, es imprescindible a la hora de hablar de prevención, intervención y reinserción. Las leyes son limitadas a la hora de resolver conflictos y dejan al componente comunicacional entre las partes involucradas a un lado, mientras que herramientas o prácticas como la mediación devuelven a los sujetos la creencia de que es posible resolver un conflicto por su propia intervención (Gordillo Santana, 2007). Prácticas cómo las que ofrece el modelo restaurativo proponen un cambio cultural en dos ámbitos fundamentales: en el modo de responder al conflicto que supone la delincuencia en una sociedad y en el forjamiento de nuevas sensibilidades en los integrantes de la misma (Tamarit Sumalla, 2012).

Consideramos que este cambio de paradigma es fundamental y también necesario para la sociedad actual, aunque por supuesto que debemos ser conscientes de las resistencias que, como en todo, cambio aflorarán desde todos los ámbitos y es entonces donde la educación entrará en juego, para luego finalmente poder instaurar un nuevo modelo de entendimiento y resolución de los conflictos sociales. Es debido a estas cuestiones que nos interesamos particularmente en el sistema restaurativo, fundamentalmente porque creemos que se trata de un modelo más apropiado para regular los efectos de la delincuencia y más acorde a lo que los estándares y normativas internacionales sugieren y recomiendan para el tratamiento de justicia juvenil.

\section{Referencias}

Aertsen, I., Bolívar, D., De Mesmaecker, V., Lauwers, N. (2011). Restorative justice and the active victim: exploring the concept of empowerment. Temida, Journal of victimization, human rights and gender, 14(1), 5-19.

Barton, C. (2000). Empowerment and retribution in Criminal Justice.En H. Strang \& Braithwaite, J. (Eds.), Restorativejustice. Philosophy to practice. (pp. 55-76) Burlington: Ashgate.

Fattah, E. (1998). Some reflections on the paradigm of restorative justice and its viability for juvenile justice. En L.Walgrave (Ed.), Restorative justice for juveniles. Potentialities, risks and problems for research. (pp. 389-401).Bélgica:Leuven University

Fumeiro, J., López, F., Gómez, D., De Achá, Rm. (2011). Violaciones de Derechos Humanos en los sistemas de justicia penal juvenil. (DNI Informe de investigación) Recuperado de http://www.dnijusticiapenaljuvenil.org

Garland, D. (2007). La cultura de las sociedades con altas tasas de criminalidad. Algunas precondiciones de las políticas de seguridad ciudadana. En D. Garland (Ed.), Crimen y castigo en la modernidad tardía (pp. 205-273). Bogotá D.C.:Siglo del hombre. 
Geudens, H. (1998). The recidivism of community service as a restitutive judicial sanction in comparison with the traditional juvenile justice measures. En L.Walgrave (Ed.), Restorativejusticefor juveniles. Potentialities, risks and problems for research. (pp.335-350). Bélgica: Leuven University

González Tascón, M.M. (2010). El tratamiento de la delincuencia juvenil en la Unión Europea. Hacia una futura política común. $\left(1^{\mathrm{a}}\right.$ ed.). Valladolid: Lex Nova.

Gordillo Santana, L.F. (2007). La justicia restaurativa y la mediación penal. Madrid: Lustel.

Juanche, A., \& Palummo, J. (2012). Hacia una política de Estado en privación de libertad. Diálogo, recomendaciones y propuestas. Uruguay: SERPAJ y Observatorio del Sistema Judicial.

Ley Presupuestal No. 18.719 (2010). Recuperado de http:// www. parlamento.gub.uy/leyes/AccesoTextoLey. asp?Ley=18719\&Anchor=

López, A., \& Palummo, J. (2013). Delincuencia juvenil en la ciudad de Montevideo. Observatorio del Sistema Judicial. Montevideo: Fundación Justicia y Derecho.

Marshall, T.F. (2003). Restorative justice: an overview. En $\mathrm{G}$. Johnstone (Ed.), A restorative justice reader (pp. 28-45). Cullompton, Devon, UK: Willan Publishing.

Medina, J. (2003). Inseguridad ciudadana, miedo al delito y policía en España. Revista electrónica de Ciencia Penal y Criminología. Recuperado de http://criminet. ugr.es/recpc/10/recpc10-07.pdf

Pascual, E. (2013). Restorative justice at the post-sentencing level in prison settings: promising practices around Europe.Trabajo presentado en la International conference Restorative Justice at post-sentencing level; supporting and protecting victims. Centre of Legal Studies and Specialized training. Barcelona. España

Pellon Perez, M., \& Palladino, M. (2011). La "Mano dura" no resuelve el problema de la delincuencia juvenil. Estudio Criminal. Archivos de Criminología, Criminalística y Seguridad privada. Vol. VII. Recuperado de: www.somecrimnl.es.tl

Put, J., Vanfraechem, I., \& Walgrave, L. (2012). Restorative dimensions in Belgian Youth Justice. Youth Justice 12(2). Recuperado de http://yjj.sagepub.com/content/12/2/83

Redondo Illescas, S. (2010). Manual para el tratamiento psicológico de los delincuentes. Madrid. Ed. Pirámide.

Segovia Bernabé, J.L. (2010). Mediación penal comunitaria y justicia restaurativa. Perspectiva ética y jurídica. En J. L.Segovia Bernabé (Ed.), Mediación penal y penitenciaria. 10 años en camino. (pp. 17-56) Madrid: Art\&Press

Stutzman Amstutz, L. (2009). The Little book of Victim offender conferencing. Bringing victims and offender together in dialogue. Estados Unidos: Good books.
Stutzman Amstutz, L., \& Mullet, J. H. (2005). Restorative discipline for schools. Teaching responsibility; creating caring climates. Estados Unidos: GoodBooks.

Subijana Zunzunegui, I.J. (2012). El paradigma de la humanidad en la justicia restaurativa. [Encuentro internacional en homenaje al Prof. Dr. Dr. H.C. Antonio Beristain] Revista Cuaderno del Instituto Vasco de Criminología. Hacia una justicia victimal. No. 26, 143-153.

Tamarit Sumalla, J. (2012). La justicia restaurativa: Concepto, principios, investigación y marco teórico. En J. Tamarit Sumalla (Ed.), La justicia restaurativa: desarrollo y aplicaciones. Estudios de Derecho Penal y Criminología. No 122,3-60.

Torres Rosell, N. (2006). La pena de trabajos en beneficio de la comunidad. Reformas legales y problemas de aplicación. Valencia: Tirant lo Blanch.

Trépanier, J. (2000). Restorative Justice: a question of legitimacy. En The European Forum for victim-offender mediation and Restorative Justice (Eds.). Victim-offender mediation in Europe.Making restorative justice work Leuven (pp. 55-73). Bélgica: Leuven University Press.

Walgrave, L. (2001). On restoration and punishment: favourable similarities and fortunate differences. En A. Morris \& G. Maxwell (Eds.), Restorative justice for juveniles. Conferencing, mediation \& circles. (pp. 17-37). Oxford-Portland, Oregon: Hart.

Walgrave, L. (2007). Restorative Justice: an alternative for responding to crime?. En S. Shoham, O. Beck \& M. Kett, (Eds.). International Handbook of Penology and Criminal Justice. (pp. 613-689). Florida:Taylor \& Francis Group.

Walgrave, L. (2008). Restorative justice, self-interest and responsible citizenship. Cullompton: Willan Publishing.

Wright, M. (1996).Justice for victims and offenders. A restorative response to crime. ( $2^{\mathrm{a}}$ ed.) Winchester: Waterside Press.

Wright, M. (1998). Victim/offender conferencing. The need for safeguards. En L. Walgrave, Restorative justice for juveniles. Potentialities, risks and problems for research (pp. 75-91). Bélgica: Leuven University Press.

Wright, M. (2003). Is it time to question the concept of punishment? En L. Walgrave, Repositioning restorative justice. (pp. 3-23 ). Cullompton: Willan Publishing

Zehr, H. (2002). The Little book of justice and peacebuilding. Pennsylvania: Good books.

Zehr, H. (2005). Changing lenses. A new focus for crime and justice. Pennsylvania: Herald Press.

Para citar este artículo:

Barboni Pekmezian, L., \& Valls Prieto, J. (2014). La reparación del daño en la justicia penal. Ciencias Psicológicas VIII (2): 199 - 207 